\title{
REALIDAD Y TÉCNICA EN ZUBIRI ${ }^{1}$
}

\author{
RICARDO ESPINOZA LOLAS, PAULA ASCORRA COSTA, \\ PAMELA SOTO GARCÍA \\ Pontificia Universidad Católica de Valparaiso
}

\begin{abstract}
RESUMEN: Este artículo profundiza en un tema muy relevante hoy, esto es, qué es la técnica, cómo acontece, cómo se desarrolla, cómo se articula con el hombre y cómo con la naturaleza. Tal concepción de la técnica, Xavier Zubiri la dejó bosquejada de modo explícito en la década de los 50 del siglo pasado (en uno de sus tantos cursos), pero tal concepción fue absolutamente renovada en los 80 a través de su trilogía Inteligencia sentiente y el nuevo horizonte filosófico por él abierto: la «noología». Y en tal renovación en torno a qué es la técnica se levanta un modo de ser técnico propio del hombre que acontece en la intelección misma de lo real y tal modo es el que nos permite ser viables en este mundo.
\end{abstract}

PALABRAS CLAVE: Zubiri, técnica, realidad, actualidad, inteligencia.

\section{Reality and Technique in Zubiri}

ABSTRACT: This article deals with a very relevant topic today, that is, what is art, what happens, how it develops, how it fits and how the man with nature. Such a conception of art, Xavier Zubiri left explicitly outlined in the 50s of the last century (in one of his many courses), but this conception was absolutely renovated in the ' 80 s through his trilogy Intelligence and sentient new philosophical horizon it open: the «noología». And in such renewal around what is a technical way of being own technical man happens in the same intellection of reality and so is what allows us to be viable in this world rises.

KEY WORDS: Zubiri, technique, actuality, reality, intelligence.

\section{INTRODUCCIÓN}

El problema de la técnica es uno de los problemas que más nos preocupan hoy en día. Para Zubiri es un problema crucial, pero en apariencia no lo trabajó temáticamente, esto es, porque solamente en el curso El problema del hombre (1953-1954), curso inédito, aparece de modo explícito el tema de la técnica en una lección (13 de abril de 1954). Nosotros creemos que esta impresión es totalmente errada. La técnica, como problema (como le gustaba a Zubiri, de corte siempre fenomenológico, tratar sus asuntos de investigación) es un problema que está totalmente presente y visible en su obra a lo largo de muchas décadas $^{2}$. Pero se expresa como el problema de la articulación entre saber y hacer, esto es, la articulación entre la inteligencia y el mundo. Pues en esa articulación es donde se da un trato con las cosas en tanto que reales y en ese trato libre se modifican las cosas y se inventan todo tipo de instrumentos para que el hombre pueda hacerse cargo de sí mismo: «... el problema central que las cosas biri».

1 Este artículo es parte del Proyecto Fondecyt N 1140973: «Realidad y técnica en Zu-

2 Sobre este tema, véase el excelente trabajo de A. GonzÁLEz (2010), «La reflexión de Zubiri sobre la técnica», Rocinante, 5, 33-62. Aquí se puede ver a nivel genealógico lo que Zubiri a lo largo de los años fue trabajando en torno a la técnica. 
nos plantean cuando el hombre quiere hacer su vida. Por razones intrínsecas y por razones históricas, llamemos a esta unidad con un nombre, que no designa una solución sino el título de un problema: la téchne, la técnica. Expresa tan sólo la unidad intrínseca entre el saber y el hacer. Y es menester considerar el problema que esta unidad intrínseca plantea» ${ }^{3}$.

$\mathrm{Y}$ es este problema el que queremos indicar someramente en este artículo. Se trata de repensar la técnica desde el horizonte de la noología zubiriana, esto es, Inteligencia sentiente (1980-1983). Solamente desde el estudio de la inteligencia sentiente, y esta es nuestra hipótesis, es posible pensar a la altura de los tiempos cómo acontece la técnica, qué es y cómo se expresa. Y para ello debemos entender la inteligencia sentiente en sus tres momentos estructurales: aprehensión primordial de realidad (APR), logos sentiente y razón sentiente. Y a la luz de estos tres momentos ver cómo se da la articulación entre inteligencia y cosas a través de la APR, del logos sentiente y la razón sentiente. Y tal articulación tendrá que ser vista en miras de la dominancia de la inteligencia sobre las cosas reales (APR), el diseño de instrumentos (Logos) y la invención de lo real (Razón). Para ello son tres los conceptos básicos que estarán a la base de cada uno de estos momentos: actualidad, campo y mundo; pero señalaremos tales conceptos solamente desde la perspectiva de la técnica ${ }^{4}$. En la APR tendremos que analizar en el concepto de actualidad, la co-actualidad entre inteligencia y lo real, en el logos se tendrá que analizar en el concepto de campo la postulación libre de lo real a través de sus formas de diseñar y, finalmente, en la razón se tendrá que estudiar en el concepto de mundo la invención de lo real.

El problema de la técnica es ni más ni menos que sumergirnos en el fundamental problema de la inteligencia, pero de la inteligencia sentiente en su trato libre con las cosas y en ese trato y rodeo por lo irreal la inteligencia forja instrumentos que buscan dar con un modo de estar en la realidad de forma más adecuada para el hombre ${ }^{5}$. Y por ende, desde Zubiri, el problema de la técnica no es de suyo negativo ni menor para la filosofía ${ }^{6}$; sino todo lo contrario, es un diálogo profundo no solamente con la filosofía sino con las ciencias y las artes.

3 ZubiRI, X. (1986), Sobre el Hombre. Madrid: Alianza, p. 331. [En adelante SH]

4 Para un estudio detallado de estos conceptos, véase el Capítulo Segundo del libro: «Realidad y "de suyo" como lo otro que nos apropia», en R. Espinoza (2013), Realidad y ser en Zubiri. Granada: Comares, 154-260.

5 Véase, de la Trilogía acerca de la técnica de Stiegler su primer volumen. En este volumen nos habla de todo lo que acontece en la técnica en tanto instrumentos. B. STIEgLer (2003), La técnica y el tiempo I: El pecado de Epimeteo. País Vasco: Hiru.

6 Véase, el bello y profundo libro de J. Conill (1991), El enigma del animal fantástico. Madrid: Tecnos. Y su artículo "Naturaleza humana y técnica», en F. ABel y C. CAÑón (eds.) (1993), La mediación de la filosofía en la construcción de la bioética, Madrid, 124-131. También son excelentes los trabajos de FeIJóo, J., «Ciencia y técnica», en González DE Posada, F. (1983), Zubiri: pensamiento y ciencia, Fundación Santander: Santander, 149-176. - «Zubiri y la técnica», en AA.VV. (1986), Homenaje a Xavier Zubiri (1898-1983), Madrid: Universidad Complutense, 23-28. Y por último es muy bueno el artículo de Manzano, J. G. (1984), «La técnica en Zubiri», Verdad y vida, 42, 57-70. 
Pues de lo que se trata es de crear, producir formas de estar en la realidad que sean más plenas para el hombre.

Nuestro marco teórico es la inteligencia sentiente de Xavier Zubiri, como fue formulada al final de su vida en la obra noológica de 3 volúmenes titulada Inteligencia sentiente (1980-1983). Pues es en ella donde se jugará todo el problema de la articulación entre saber y hacer que es la esencia misma de la técnica. Aunque en sus primeros escritos habla de forma rápida de la técnica no hay una profundización conceptual ${ }^{7}$. Por esta razón en la Trilogía, la obra, por una parte, madura del pensador y, por otra, la obra con más plasticidad y riqueza, de la Inteligencia veremos toda la capacidad de Zubiri para dar con conceptos muy ricos que nos permitirán entender el fenómeno de la técnica en nuestros días.

¿Qué es la inteligencia sentiente? ${ }^{8}$ Si podemos responder a esto con claridad, luego en nuestra meditación podremos sumergirnos en detalle y ver cómo se da lo técnico en sus distintas vertientes a la luz de esa inteligencia. El filósofo español describe el hecho mismo de lo que se impone en la aprehensión humana y lo hace intentando no construir teóricamente nada acerca de este hecho radical e innegable (es su supuesto noológico, como sabemos). Y este análisis se lleva a cabo de modo detallado en su Trilogía. Además de la Trilogía, es fundamental pensar con el curso El problema del hombre de 1953-1954 (en el que habló explícitamente de la técnica). La Trilogía nos indica de forma detallada y precisa que en el acto de inteligir mismo se nos impone con toda su fuerza la realidad: «... mi estudio va a recaer sobre los actos de inteligir y de sentir en tanto que

7 Por ejemplo, el filósofo dice en 1921 en su tesina presentada en Lovaina El problema de la objetividad según Husserl. I. La lógica pura: «... lo propio del psicologismo es confundir las normas técnicas con las normas ideales; las primeras son psíquicas porque están fundadas en el acto de conocer la verdad, mientras que las segundas son lógicas porque están fundadas en la verdad conocida», X. ZuBIRI (1994), Los problemas fundamentales de la metafísica occidental. Madrid: Alianza, p. 53. [PFMO] Lo mismo acontece en su tesis doctoral de 1923 titulada Ensayo de una teoría fenomenológica del juicio. Véase, PE, p. 221. Y se puede rastrear un uso similar de la técnica en los cursos universitarios de Zubiri como también en su primera gran obra, el ensayo realizado con múltiples textos, Naturaleza, Historia, Dios: «en el científico, sus métodos comienzan, a veces, a tener muy poco que ver con su inteligencia. Los métodos de la ciencia van convirtiéndose, con rapidez vertiginosa, en simple técnica de ideas o de hechos - una simple metatécnica-; pero han dejado de ser lo que su nombre indica: órganos que suministran evidencias, vías que conducen a la verdad en cuanto tal». X. ZuBIRI (2007), Naturaleza, historia, Dios (1944). Madrid: Alianza, p. 367 [En adelante NHD]. Y en los Cursos algo similar. Véase, X. Zubiri (2007), Cursos Universitarios. Volumen I, Madrid: Alianza, p. 108.

8 Respecto de este tema, ya se ha escrito mucho. Por parte de los autores de este artículo, véase, R. EsPinoza (2005), «Realidad y Logos. ¿Es Zubiri un pensador posmoderno?», Philosophica, 27, pp 109-157. R. Espinoza (2006), «Zubiri y Husserl. Una crítica desde el carácter físico a la intencionalidad». Cuadernos Salmantinos de filosofía, 341-367. 
actos (kath'enèrgenian), y no en tanto que facultades (kàta dýnamin)... [se trata] de la estructura interna del acto de inteligir» ${ }^{9}$. Esto será fundamental para entender la técnica no como algo externo al hombre, sino como un momento estructural del carácter mismo intelectivo del hombre en su trato con las cosas reales; tal carácter va de la mano del sentir. Así Zubiri lo decía en 1973: «... en el sentir humano, esto es, en la intelección sentiente, la impresión no sólo impresiona al animal que yo soy, sino que es impresión de algo que está formalmente presente impresivamente como real. Es lo que llamo impresión de realidad $»^{10}$. Si nos damos cuenta, de inmediato se da esta articulación entre inteligir y la cosa, donde la cosa misma es la que abre todo el acto mismo intelectivo.

Tal inteligencia sentiente, como es bien sabido, se expresa de un modo triple y dinámico a la vez: aprehensión primordial de realidad, logos y razón. Y estos tres momentos de expresión de la inteligencia sentiente estarán presentes en este artículo, pero más que hablar de estos tres momentos (que no es el fin de este artículo), lo que se pretende es algo más simple, solamente mostrar cómo estos momentos indican una dimensión de la técnica. Esto es crucial cuando pensamos la técnica en detalle en su momento estructural del carácter mismo dinámico en que el hombre se hace cargo de la realidad por medio de su inteligencia sentiente: "No solamente la realidad se aprehende en aprehensión primordial como "de suyo", entendido como un "de suyo que es", un "de suyo que está siendo tempóreamente", sino que la misma aprehensión primordial queda, como es obvio, "tocada" por ese carácter tempóreo... la intelección misma se desplegaría en sus momentos ulteriores de logos y razón por motivos dinámicos no solamente derivados del carácter impresivo de la aprehensión primordial sino también por motivos tempóreos $»^{11}$. Ese carácter impresivo tempóreo de lo real aprehendido en aprehensión primordial va a ser una de las fuentes del desarrollo ulterior de la inteligencia como logos y razón. El carácter tempóreo sentido en aprehensión primordial da el carácter modal mismo del ser sentido como el «color» de la realidad, los «tonos» de la luz del ser (no olvidemos que el ser es la «luz» de la realidad y ésta es la «luminaria» misma) ${ }^{12}$. Ese «color» sentido en la luz que está siendo la realidad nos permite distender y desplegar lo sentido porque el tiempo en su presentarse a la luz de su ser queda presente, en esa misma luz, como «color» de la realidad; «color» que hace visible el presente mismo que se despliega de la cosa sentida; el «color», esto es, el

9 X. ZuBIRI (2006), Inteligencia sentiente. Inteligencia y Realidad (1980). Madrid: Alianza, p. 20. [En adelante IRE]

10 X. Zubiri (2008), Espacio. Tiempo. Materia. Madrid: Alianza, 152-153.

11 R. Espinoza (2006), Realidad y tiempo en Zubiri. Granada: Comares, p. 350.

12 Véase, R. Espinoza (2013), op. cit., pp. 410-414. 
tiempo lanza al hombre ${ }^{13}$ a hacerse cargo de lo real sentido (es cosa de pensar, por ejemplo, en todo lo que ha sido el sol para el hombre, pero nos referimos no a un sol en el sentido de una construcción cultural, sino, anterior a eso, a un sol sentido en aprehensión primordial de real, un sol "de suyo que es» y, además, se siente de modo tempóreo). El «color» del ser, su tiempo, dará una buena idea para ver cómo la inteligencia se hace cargo de eso real sentido tempóreo y en ello mismo, dicho "color», dicho "presente en mientras» requiere a la inteligencia a ir creando formas de dominio de ese presente ${ }^{14}$, por ejemplo, la propia mano se vuelve intelectiva a luz de lo sentido como real y ella se vuelve configuradora de lo real en el pasar de su día y configuradora en el sentido más simple del vocablo.

Ese carácter impresivo tempóreo (sentiente) es parte del «movimiento» mismo en que el hombre por sentir las cosas como reales queda «hacia» todo lo real lanzado dinámicamente a afirmar y fundamentar; y esta asimetría entre lo real y el sentir, entonces, acontece como un "prius» de lo real sobre el sentir. En tanto real sentido será la base estructural, creemos, del carácter técnico de nuestra inteligencia como medio para hacerse cargo de la realidad. Pues si no estuviera este carácter técnico no sería del todo viable el hombre como tal. Aunque esta estructuración técnica es fundamental para que el hombre sea hombre desde la hominización misma (de allí la creación de utensilios y la importancia, por ejemplo, de la mano) no es del todo suficiente para ser plenamente hombre ${ }^{15}$.

Entonces en el análisis del primer momento del sentir intelectivo, en cuanto aprehensión primordial de realidad, se da esa «actualidad» asimétrica con lo sentido que es lo que inaugura lo técnico propiamente como tal. Como dice Diego Gracia de forma muy clara: "Lo aprehendido se me actualiza como "de suyo". El "de suyo" no es el "en sí" del realismo ingenuo, ni el "en mí" del idealismo, también ingenuo. El "de suyo" es realidad, pero realidad en la aprehensión, no allende ella. A pesar de lo cual, en el "de suyo" hay un momento que Zubiri llama de "prius". Se ha discutido mucho lo que puede significar ese término. Espinoza Lolas da una explicación que a mí me parece definitiva. En la aprehensión la iniciativa no la toma la conciencia, como sucedía en Husserl, sino que es la propia realidad, el propio "de suyo" el que sale por sus fueros y se impone. Lo originario no es ningún tipo de "posición”,

13 Véase, R. Durán, R. Espinoza, O. Orellana et al. (2009), «Tiempo y cosa: La influencia de Einstein en el pensamiento de Zubiri en torno al tiempo lineal», Pensamiento, 246, pp. 809-832.

14 Véase, el capítulo dedicado al tiempo modal en el libro: R. Espinoza (2006), op. cit., pp. 120-210. Aquí trato con detención los rasgos del tiempo modal y ahí podemos ver con claridad su imbricación con el ser y la realidad.

15 Zubiri en 1964 indica claramente lo siguiente: «Probablemente, toda la ciencia y toda la técnica del mundo actual, que son un prodigioso enriquecimiento de la sustantividad humana (hay que consignarlo taxativamente), ha puesto más en claro la imposibilidad de conseguir el bien del hombre como realidad moral en el dominio técnico del hombre». X. ZUBIRI (1992), Sobre el sentimiento y la volición. Madrid: Alianza, p. 312. 
como sucedía en el idealismo, sino la "imposición" de la propia realidad. Eso es lo que Zubiri llama "fuerza de imposición" »" . En esto, la actualidad es fundamental para entender de entrada la articulación entre inteligencia y realidad (tema fundamental en la historia de la filosofía que se puede rastrear explícitamente desde Parménides a Heidegger). Y de ahí cómo se echa a andar toda la actividad humana en su hacerse cargo de las cosas y de sí misma: «La totalidad de la técnica ha nacido de hacerse cargo de la realidad; es decir, del movimiento real y de las modificaciones que el hombre con sus movimientos introduce en la realidad ${ }^{17}$.

Zubiri se propone examinar el acto mismo de aprehensión humana para dar con el sentido originario de la realidad y de cómo nos hacemos cargo de ella. Aquí ya se da el nacimiento de la técnica: «... la técnica nace de una inteligencia sentiente, la cual tiene que hacerse cargo no solamente de las cosas que están ahí y me afectan, sino también de lo que efectivamente he hecho con las cosas cuando me muevo ${ }^{18}$. En el análisis descriptivo del acto mismo de aprehensión se desvela originariamente que el hombre «está»absolutamente constituido y sumergido en y por la realidad por el mero hecho de «estar» sintiendo: «... la verdad es que estamos instalados modestamente, pero irrefragablemente, en la realidad $»^{19}$. Y por eso el hombre se echa a andar y se hace cargo de la realidad y en ello de sí mismo. La aprehensión propia del hombre, como hemos dicho, es una aprehensión de tipo impresiva, pero lo que se siente en esa impresión es la realidad misma de los contenidos. Se sienten los contenidos de un modo determinado, se sienten como "de suyo" lo que son en la aprehensión. Independiente del acto de aprehensión sentiente, se siente en ese mismo acto algo que es formalmente anterior ("prius») a él, el mero carácter de realidad del contenido; esto es, se siente el contenido en la formalidad de realidad, se siente como «de suyo». La impronta de lo real en la realidad como "prius» es lo que permitirá que luego el logos pueda trabajar libremente en el campo, en el diseño de las cosas. Lo interesante sería estudiar, en detalle y esto excede este artículo, cómo en esa liberación del contenido del logos, afirma y diseña lo real en el campo y así ya lo modifica y transforma de algún modo, esto es, lo técnico en su segundo momento de diseño de la realidad. Y este carácter real de la aprehensión mienta el carácter mismo físico que se nos impone como lo absolutamente otro «en» la misma aprehensión sentiente. De aquí resulta algo muy importante para nuestra investigación sobre la técnica.

16 D. Gracia (2006), «Prólogo», en R. Espinoza (2006), op. cit., p. XIX.

17 SH, p. 339.

18 SH, p. 339.

19 IRE, p. 15. 
La aprehensión humana no es solamente impresiva, sino que lo es eminentemente de realidad. El hombre siente impresivamente la realidad y esto no lo podemos olvidar, pues es el fundamento que luego se hable de una «inteligencia sentiente». El hombre por ser hombre siente impresivamente el carácter físico y real.

Esto es, el «de suyo» de las cosas: «... si la formalidad de lo sentido consiste en que esto sentido lo sea como algo "de suyo", "en propio": es la formalidad de reidad o realidad. Ahora bien, aprehender realidad es lo formalmente propio de la intelección. Por tanto, aprehensión impresiva, impresión de realidad, es formalmente intelección sentiente $»^{20}$. Este pasaje es fundamental para darnos cuenta de cómo desde el carácter mismo físico sentido se abre para el hombre, ulteriormente, su trato sentiente y modificador (manejo) de la realidad ${ }^{21}$. Zubiri en sus Lecciones de Madrid de 1933-1934 indicaba con claridad: «Las cosas no son poderes, sino dóciles instrumentos. La acción humana no es un simple "manejo" o utilización que sojuzga las cosas. No se alberga en las cosas, las utiliza»"22. El logos se las ha con lo real sentido. Un análisis del acto de aprehensión en cuanto acto rompe radicalmente la inmediatez del desliz propio de la estructura necesaria misma de nuestra lengua indoeuropea, esto es, "predicar» a un «sujeto» ${ }^{23}$. Y así nos percatamos de que nuestra intelección

$20 \quad$ IRE, p. 282

21 En la lección del 13 de abril de 1954 cuando Zubiri habló explícitamente de la técnica aparece en la edición el término «manipulación» como la palabra que describe el trato de la inteligencia con las cosas, pero cuando se estudia el manuscrito que está en la Fundación Xavier Zubiri, se puede ver que el propio Zubiri había corregido esto y colocaba la palabra «manejo». Esto no es menor y creemos que está en mayor sintonía con lo que pensaba Xavier Zubiri. El pensador español siempre vio positivamente el problema de la técnica a diferencia de Heidegger.

22 X. Zubiri (2012), Cursos Universitarios, Volumen III. Madrid: Alianza, p. 20.

23 Véase, el detallado estudio en torno al tema del Lenguaje de R. Espinoza (2013), «Capítulo Primero. Realidad y el problema del Lenguaje», en Realidad y ser en Zubiri. Granada: Comares, pp. 59-146. Por ejemplo: «el logos no es realmente eso que se viene pensando desde antaño. El logos como un afirmar desde lo físico campal es un afirmar que se modula, se expresa de una determinada manera. Estamos situados ya en un campo físico que nos estructura lo que decimos y pensamos de la realidad. Por tanto, no solamente se dice algo respecto de algo, como se viene insistiendo desde siglos de modo rotundo, sino que se dice desde un campo físico abierto por la misma aprehensión primordial y, además, se dice en una manera determinada. No es lo mismo, por ejemplo, expresar algo de modo predicativo que "antepredicativo". Pero esto no es todo, porque incluso lo que se dice de una manera determinada (ya predicativa o no) está a su vez modulado por una mentalidad propia (filosófica, poética, religiosa, etc.), la cual se abre desde la esencia de la razón en su concreción. Y esta mentalidad, a su vez, está cualificada extrínsecamente por componentes sociales, históricos, etc. (no es lo mismo ser semita que heleno). Luego al decir algo respecto de algo tenemos que ver que se está diciendo algo desde el campo físico (que es lo mismo que decir el mundo sentido, de allí que siempre pensemos al logos y a la razón en una unidad constructa), algo que se está expresando en una estructura propia, pero que tal estructura está siendo tocada ya por una 
es radicalmente una inteligencia sentiente $\mathrm{y}$, en esto, surge la realidad como formalidad. Porque la realidad ya no es afirmada a la luz del predicar que «inhiere» accidentes sobre un sujeto que está más allá de ellos, sino que es afirmada en una unidad en que todos los contenidos sentidos en la aprehensión son articulados entre sí. Y esto, creemos, que para entender la técnica es fundamental, porque las cosas reales serán afirmadas como un sistema de notas estructuradas de un modo muy determinado, en donde ya no son necesarios los sujetos y los accidentes para describirlas: «... para una inteligencia sentiente, la realidad no es jectum (ni subjectum ni objectum), sino que lo real es lo que tiene la formalidad del "de suyo", sea una nota un sistema de notas sentidas en su realidad $»^{24}$. La realidad al ser descrita correctamente sin confusión, nos muestra su sentido como una actualidad «constructa». Con esto Zubiri está en el horizonte postmoderno, pues está pensando desde el todo, desde una «trama» o articulación de momentos dinámicos entre sí, en donde no se da un «punto» o «sujeto» que sea la base hegemónica de todo ${ }^{25}$. Lo que se da en el logos campal es una cierta dominancia de momentos respecto de otros momentos. El «prius» se expresa como dominancia de los momentos sentidos los unos sobre los otros; por esto se da: «... un cierto constructo en donde dos o más notas tienen distintos modos de dominancia entre sí; una dominancia que siempre opera como «prius» de un momento en los otros» ${ }^{26}$. Y es esta dominancia que está sentida en la intelección sentiente y la que se afirma en el logos sentiente es la que va dando figura al hacer técnico de la propia inteligencia para con las cosas. En el momento inicial de la aprehensión primordial de realidad lo real está sentido en su mero carácter de real, en esa actualidad de lo real. Y ese momento es el que desencadena lo técnico en el logos y se da su afirmación

mentalidad en su momento primario y en su momento derivado. Pues querer afirmar algo de modo predicativo o no está sujeto, por ejemplo, a querer afirmarlo porque estoy situado de manera poética o científica respecto de ese algo. Si es un modo u otro será mejor afirmar de tal o cual manera. A lo mejor si es poético será mejor una manera ante-predicativa. Y también en este decir algo respecto de algo está la componente derivada de la mentalidad, pues es obvio que si soy semita, por condiciones sociales e históricas de ello, estaré más propenso a afirmar mi mentalidad científica o no de un modo u otro. Es claro que el modo predicativo que inhiere accidentes en un sujeto por medio del enlace del verbo pierde toda su fuerza en el semita, y éste no es, para nada, el caso del heleno. Entonces podemos ver que en el problema del decir, en general, y en el decir filosófico, en especial, se están articulando al mismo tiempo aprehensión primordial, logos y razón», R. EsPinoza (2013), op. cit., pp. 123-124.

24 IRE, p. 207.

25 «¿Es Zubiri un pensador posmoderno? Creemos que sí... Y lo haremos desde su pensamiento último (desde Inteligencia sentiente); un pensamiento anclado en una manera de decir que intenta no ser ni predicativa ni fenomenológica, pues busca radicalmente no quedar atrapado en las redes del "sujeto"». R. Espinoza (2004), «Realidad y logos. ¿Es Zubiri un pensador posmoderno?», Philosophica, 27, p. 110. Véase, también, R. Espinoza (2006), «Acerca de los "Orígenes y Límites" del Lenguaje: El Mito de Babel y el Poema de Parménides», Cognitio, 7, pp. 77-99.

26 R. Espinoza, P. Ascorra, y E. Vargas (2013), "Realidad y actualidad. Una primera aproximación al tema del cuerpo», Arbor, 189, p. 5. 
en diseño. Y es eso lo que ha hecho el hombre a través del campo sentido. La actualidad se nos vuelve campal y es en ese campo donde se tejen las tramas y las dominancias de unos momentos sobre otros. El logos no puede ser una estructura que reposa sobre sí misma, esto es inaceptable para Zubiri, porque reposa sobre lo que se impone en la aprehensión primordial. Se afirma intelectivamente algo que se nos impone desde el campo físico abierto por la propia aprehensión primordial: «El campo no es ni un concepto ni una relación. Es un momento físico de lo real en su actualidad... Y en este campo en que ya estamos por la aprehensión primordial, es donde campalmente inteligimos lo que una cosa es en realidad $»^{27}$. Es en este campo donde la realidad se nos actualiza de forma libre y en cierto sentido se des-realiza (se vuelve irreal) ${ }^{28}$ y se hace libre para ser diseñada con otros contenidos. Zubiri lo dice muy claramente en 1968: «... el hombre, en muchas dimensiones de su vida, no puede ser realmente lo que es sino pasando por el rodeo de la irrealidad ${ }^{29}$. Aquí está una fuente muy importante de invención técnica de la realidad: «Este ámbito de desrrealización es un ámbito físico de la aprehensión... La intelección, en que "la" realidad se actualiza, no es una intelección vacía, huera, sino que es una intelección en la cual en la medida que se actualiza el ámbito se van elaborando en él unas o varias simples aprehensiones ${ }^{30}$. Y en esta desrrealización en el campo físico sentido es donde juega la libertad para ir produciendo contenidos en tramas de dominancias. Y aquí ya se nos manifiesta el carácter formalmente técnico de la inteligencia en su trato con las cosas, lo que es un rasgo muy importante: «... es una realización constitutivamente libre. Lo irreal no es una cosa mental tratado como si fuera real, pero tampoco es una cosa física: es cosa libre» ${ }^{31}$. Y aquí ya tenemos, creemos, lo formalmente técnico. El carácter de invención de la realidad ${ }^{32}$. Esto es fundamental para Zubiri y nos permite ver cómo el pensador español piensa en el fondo la realidad misma, pero como formalidad de realidad. Y aquí ya no tenemos ningún rasgo de un realismo ingenuo, de ninguna especie.

Finalmente tenemos el momento de la razón sentiente. Aquí es el mundo el que hace presente las cosas reales. El mundo, que ya ha sido diseñado por el logos, ahora se trata de desplegarlo. Y aquí la razón tiene un trato con lo real de forma muy radical. Ante la razón se da formalmente la experimentación y libre construcción en el mundo, en la profundidad del mundo se da lo que sea realmente la cosa. Y ahí, en esa experimentación, la técnica se expresa de una forma

27 X. Zubiri (1982), Inteligencia y logos. Madrid: Alianza, p. 18. [En adelante IL]

28 X. Zubiri (1985), El hombre: lo real y lo irreal. Madrid: Alianza, p. 22.

29 X. Zubiri (1989), Estructura dinámica de la realidad. Madrid: Alianza, p. 238.

30 IL, p. 94.

31 IL, p. 94.

32 Se puede ver una influencia clara sobre Zubiri de su amigo Bergson, pero con claros matices de diferencia. Véase, por ejemplo, H. Bergson (2012), La evolución creadora. Buenos Aires: Cactus. Y Se puede leer el buen artículo de G. Marouínez (2004), «Bergson y Zubiri», en J.A. Nicolás y O. Barroso, O. (eds.) (2004), Balance y perspectivas de la filosofía de Xavier Zubiri. Granada: Comares, pp. 419-435. 
totalmente transversal, desde las ciencias a las artes. Se experimenta lo que sea la cosa en el mundo en la medida que se le interroga por su fundamento y en tal interrogación se construye lo real: «La libre construcción es el grado máximo de libertad creadora... Yo construyo libremente a base de perceptos, fictos, conceptos y sobre todo de afirmaciones. Esto así construido, es construido en la realidad, en la realidad física misma: es la realidad campal en cuanto realidad física... Es esta realidad la que se actualiza en mis libres construcciones... La libertad no concierne aquí tan sólo al acto constructor, sino a la índole formal de lo construido mismo. La libertad no es tan sólo libertad de modificar notas ni de homologar estructuras; aquí libertad es liberación de todo lo campal para construir el contenido de la realidad profunda» ${ }^{33}$. En esto se juega todo lo que sea la técnica hoy, que no es solamente diseños de tramas en el campo sentido con distintas dominancias de unos momentos con respecto de otros. Como dice Zubiri en Sobre la esencia: "... un abismo separa nuestra técnica de la técnica antigua; no es sólo una diferencia de grado, sino una diferencia fundamental, de incalculable alcance filosófico ${ }^{34}$. Ahora hay que ver en el mundo mismo cómo se da esa «invención» de lo real; invención que sería lo propiamente técnico de nuestra era contemporánea. En un curso de 1966, Zubiri así les decía a sus estudiantes: «... la paradoja de nuestra técnica está en que fabrica artificialmente cosas naturales» ${ }^{35}$. Esta afirmación de Zubiri es realmente notable, aguda y nos deja instalados en lo que es la técnica hoy y cómo ésta es parte constitutiva del operar humano, pues no solamente modifica la naturaleza (mejor dicho, en términos actuales, la biodiversidad) sino que la fabrica y esto es distinto y más radical ${ }^{36}$. Ya no se trata solamente de una articulación entre saber y hacer a través de la inteligencia sentiente, ni tampoco diseñar y afirmar las tramas de dominancias que van configurando lo real (códigos, lenguajes, leyes, etc.), sino de lo que en verdad se trata es de inventar realidad ${ }^{37}$ que nos permitan a la larga generar nuevas formas de estar en la realidad: «Toda la técnica actual fabrica

33 X. Zubiri (1983), Inteligencia y razón. Madrid: Alianza, p. 128.

34 X. ZubiRi (2008), Sobre la esencia. Madrid: Alianza, p. 84.

35 X. Zubiri (2001), Sobre la realidad. Madrid: Alianza, p. 221. [En adelante SR]

36 En esto podemos ver uno de los puntos más distintos de Zubiri con Heidegger. Y además podemos distinguir ambas filosofías, pues en el fondo en el tema de la técnica lo que está en juego es la concepción misma de la realidad. Y aquí con Heidegger la diferencia es total. Véase por ejemplo, los siguientes textos de M. Heidegger (2003), Aportes a la filosofía. Acerca del evento. Buenos Aires: Biblos 2003; (1989), Beiträge zur Philosophie (Vom Ereignis), F. W. von Herrmann (ed.) (1989), 65, Vittorio Klostermann: Frankfurt am Main; (2001) Conferencias y artículos. Barcelona: Serbal; (1997), «Construir Habitar Pensar», Filosofía, Ciencia y Técnica, Santiago de Chile: Universitaria; (1954), «Bauen, Wohnen, Denken»,Vorträge und Aufsätze, Pfullingen; (2000), «El origen de la obra de arte», Caminos de bosque. Madrid: Alianza; (1977), «Der Ursprung des Kunstwerkes» en Holzwege, Vittorio Klostermann, Frankfurt am Main; (1954), «Die Fragenach der Technik», Vorträge und Aufsätze, Pfullingen: Günther Neske; (1994), Serenidad. Barcelona: Serbal.

37 En 1974 el filósofo nos señala: «... las formas de estar en la realidad proceden... por invención, porque hay que optar». X. ZubIRI (2002), Tres dimensiones del ser humano: individual, social, histórica. Madrid: Alianza p. 77. [En adelante TDSH]. 
innumerables cosas naturales, que son artificiales desde el punto de vista del principio que las produce, pero que son formalmente naturales desde el punto de vista de su modo de realidad $»^{38}$. Y este "punto de vista» es importante, pues como hemos dicho, cambió la concepción de realidad que es la que refleja la concepción de inteligencia sentiente y que puede expresar todo lo que está pasando ahora y que sería totalmente impensable para los griegos, medievales y modernos $^{39}$. El hombre en la actualidad es inventor y creador de insulina, por ejemplo. Y la insulina aunque sea artificial en su producción se convierte en algo natural, es de suyo natural, su nuda realidad lo es: «... la insulina así producida artificialmente por mí actúa sobre el resto de las realidades del Universo por todas y solas las notas que efectivamente posee. Tiene una nuda-realidad en virtud de la cual es nuda realidad $»^{40}$. En esto la realidad ya no es ni «en sí» ni «en mí», ni a posteriori ni a priori, sino formalidad y por ello el hombre se debe comprender desde el horizonte de la inteligencia sentiente. Pues solamente una concepción de la realidad que no sea realista ni idealista ni fenomenológica es la que nos permite comprender cómo el hombre puede ir generando cosas reales, cómo puede dar contenidos nuevos a la realidad ${ }^{41}$.

\section{ConCLusión}

Ortega, maestro de Zubiri, resuena con sus palabras: «Sin la técnica el hombre no existiría ni habría existido nunca» ${ }^{42}$. Para finalizar, entonces ¿qué es lo propio de la técnica? Zubiri hace muchos años atrás lo señala tajantemente: «Lo propio de la técnica... es hacer en una situación instrumentos que no sólo sirven para resolverla, sino que previenen todas las demás situaciones... La técnica no sólo es una modificación, es poder sobre las cosas, no sólo por lo que tienen de específicas, sino por lo que tienen de realidad» ${ }^{43}$. Y ahora es necesario investigar y desplegar esto filosóficamente a la luz de las categorías de la noología, que es el lugar propio del análisis acabado de la inteligencia, como inteligencia sentiente que nos permite ser viables en el mundo. En 1974 el filósofo nos señala: «... las formas de estar en la realidad proceden... por invención, porque hay que optar» ${ }^{44}$.

38 SR, p. 221.

39 Por ejemplo, para Aristóteles. Ya no es posible mantener la distinción entre cosas naturales (physei onta) y cosas técnicas (techne onta). ARISTóteles, Metafísica I, 1. Madrid: Gredos, 980 a 20-983 a 3. Y Aristóteles, Ética a Nicómaco, VI. Madrid: Gredos, 3-4, 1039 b $15-1040$ a 22.

$40 \quad$ SR, p. 221.

41 Véase, R. EsPinoza, E, VArgas y P. Ascorra (2013), «Realidad y actualidad. Una primera aproximación al tema del cuerpo», Arbor, 189-760, a17.

42 J. Ortega y Gasset (2008), Meditación de la técnica y otros ensayos sobre filosofía y ciencia. Madrid: Alianza, p. 3.

43 SH, pp. 339-340.

44 TDSH, p. 77. 
Si nos hemos percatado, la concepción de la técnica en Zubiri, y en especial en su último período es una concepción que tiene por nivel tres dimensiones que se articulan entre sí. En primer lugar, la técnica mienta una concepción de la naturaleza, ya no como en sí; sino todo lo contrario, una naturaleza que se asume, se modifica, se autocrea porque es una naturaleza de la mano de sus propios elementos en red que la constituyen y que van perfilando toda la realidad tal como se expresa un sistema complejo ${ }^{45}$. En segundo lugar, la técnica ni más ni menos es para nombrar lo humano desde un aspecto fundamental, esto es, es ver al hombre desde una forma de estar en la realidad que de suyo sería técnica. Antes de habitar poéticamente la tierra (como lo piensa Heidegger siguiendo a Hölderlin), y antes de habitar teologalmente la tierra (que es como el propio Zubiri piensa, siguiendo en esto la tradición de la teología y la mística.) se habita técnicamente la tierra, puesto que es la única forma y primigenia que nos podemos hacer cargo de la realidad. Y en tercer lugar, la técnica es una expresión que mienta a hombre mismo en cuanto inteligencia sentiente que se tiene que hacer cargo de su inteligencia para ni más ni menos sea viable.

\section{BibLiografía}

Aristóteles (2000), Metafísica I. Madrid: Gredos

- (2000), Ética a Nicómaco. Madrid: Gredos.

Bergson, H. (2012), La evolución creadora. Buenos Aires: Cactus.

Conill, J (1991), El enigma del animal fantástico. Madrid: Tecnos.

- (1993), «Naturaleza humana y técnica», en F. ABel y C. CAÑón (eds.) (1993), La mediación de la filosofía en la construcción de la bioética. Madrid: UPCO.

Dugue, F. (2001), Arte y espacio público. Madrid: Akal.

- (1986), Filosofía de la técnica de la naturaleza. Madrid: Tecnos.

EspinozA, R. (2006), Realidad y tiempo en Zubiri. Granada: Comares.

- (2013), Realidad y ser en Zubiri. Granada: Comares.

- (2005), «Realidad y Logos. ¿Es Zubiri un pensador posmoderno?». Philosophica, 27, 109-157.

- (2006) «Zubiri y Husserl. Una crítica desde el carácter físico a la intencionalidad», Cuadernos Salmantinos de Filosofía, xxxiII, 341-367.

- (2006) «Acerca de los “Orígenes y Límites" del Lenguaje: El Mito de Babel y el Poema de Parménides», Cognitio, 7, 77-99.

Espinoza, R., Orellana, O. (2009), «Tiempo y cosa: La influencia de Einstein en el pensamiento de Zubiri en torno al tiempo lineal», Pensamiento, 65, $\mathrm{N}^{\circ} 246,809-832$.

Espinoza, R., Ascorra, P. y VARgaS, E. (2013), «Realidad y actualidad. Una primera aproximación al tema del cuerpo», Arbor, 189-760, 1-14.

FeiJóo, J. (1983), «Ciencia y técnica», en González de Posada, F., Zubiri: pensamiento y ciencia. Santander: Fundación Botín.

45 Véanse, los dos excelente libros de Félix Duque. En estos podemos vislumbrar a la altura de los tiempos, lo que Zubiri pudo estar pensando al final de sus días de lo que es la Naturaleza. F. Duoue (2001), Arte y espacio público. Madrid: Akal, 2001; (1986), Filosofía de la técnica de la naturaleza. Madrid: Tecnos. 
- (1986), «Zubiri y la técnica», en AA.VV., Homenaje a Xavier Zubiri (1898-1983). Madrid: Universidad Complutense.

Gracia, D. (2006), «Prólogo», en Espinoza, R. (2006), Realidad y tiempo en Zubiri. Granada: Comares.

GonzÁLez, A. (2010), «La reflexión de Zubiri sobre la técnica», Rocinante, 5, 33-62.

Heidegger, M. (2003), Aportes a la filosofía. Acerca del evento. Buenos Aires: Biblos.

- (1989), Beiträge zur Philosophie (Vom Ereignis), von Herrmann, F. W. (Ed), Gesamtausgabe vol. 65. Franckfurt: Frankfurt am Main.

- (2001), Conferencias y artículos. Barcelona: Serbal.

- (1997), «Construir Habitar Pensar» en Filosofía, Ciencia y Técnica. Santiago de Chile: Universitaria.

- (1954) «Bauen, Wohnen, Denken», en Vorträge und Aufsätze. Pfullingen: Günther Neske.

- (2000), «El origen de la obra de arte», en Caminos de bosque. Madrid: Alianza.

- (1977), «Der Ursprung des Kunstwerkes» en Holzwege. Frankfurt am Main: Vittorio Klostermann.

- (1954), «Die Fragenach der Technik», en Vorträge und Aufsätze. Pfullingen: Günther Neske.

- (1994), Serenidad. Barcelona: Serbal.

Manzano, J. G. (1984), «La técnica en Zubiri», Verdad y vida, 42, 57-70.

Marquínez, G. (2004), "Bergson y Zubiri», en Nicolás, J. A. y Barroso, O. (eds.), Balance y perspectivas de la filosofía de Xavier Zubiri. Granada: Comares.

Ortega y Gasset, J. (2008), Meditación de la técnica y otros ensayos sobre filosofía y ciencia, Madrid: Alianza.

Stiegler, B. (2003), La técnica y el tiempo I: El pecado de Epimeteo. País Vasco: Hiru.

ZuBIRI, X. (1982), Inteligencia y logos. Madrid: Alianza.

- (1983), Inteligencia y razón. Madrid: Alianza.

- (1986), Sobre el hombre. Madrid: Alianza.

- (1989), Estructura dinámica de la realidad. Madrid: Alianza.

- (1992), Sobre el sentimiento y la volición. Madrid: Alianza.

- (1994), Los problemas fundamentales de la metafísica occidental. Madrid: Alianza.

- (2001), Sobre la realidad. Madrid: Alianza.

- (2002), Tres dimensiones del ser humano: individual, social, histórica. Madrid: Alianza.

- (2005), El hombre: lo real y lo irreal. Madrid: Alianza.

- (2006), Inteligencia sentiente. Inteligencia y Realidad (1980). Madrid: Alianza.

- (2007), Naturaleza, historia, Dios (1944). Madrid: Alianza.

- (2007), Cursos Universitarios I. Madrid: Alianza.

- (2008), Espacio. Tiempo. Materia (1996). Madrid: Alianza.

- (2008), Sobre la esencia (1962). Madrid: Alianza.

- (2012), Curso Universitario III. Madrid: Alianza.

Pontificia Universidad Católica de Valparaiso

respinoz@ucv.cl

Ricardo EsPinOza LOLAS, Paula Ascorra Costa, Pamela argaso García

[Artículo aprobado para publicación en este número extraordinario en noviembre de 2014] 
